\title{
Mesoscale GPS Zenith Delay assimilation during a Mediterranean heavy precipitation event
}

\author{
X. Yan ${ }^{1}$, V. Ducrocq ${ }^{1}$, P. Poli ${ }^{1}$, G. Jaubert ${ }^{1}$, and A. Walpersdorf ${ }^{2}$ \\ ${ }^{1}$ GAME-CNRM, CNRS \& Météo-France, 42 Avenue Coriolis, 31057 Toulouse Cedex 1, France \\ ${ }^{2}$ LGIT, Université Joseph Fourier, Maison des Géosciences, BP 53, 38041 Grenoble Cedex 9, France
}

Received: 31 March 2008 - Revised: 11 June 2008 - Accepted: 30 June 2008 - Published: 29 July 2008

\begin{abstract}
The impact of assimilating Zenith Total delay (ZTD) observations from a mesoscale ground-based GPS network over Western Europe is evaluated for the heavy precipitation event of 5-9 September 2005 over Southern France. The ZTD assimilation is performed using a three dimensional variational data assimilation system at the 9.5$\mathrm{km}$ horizontal resolution. Then using as initial conditions the 3DVAR analyses with and without assimilation of ZTD, we perform 2.4-km non-hydrostatic MESO-NH simulations. The results of the fine-scale simulations indicate that assimilation of ZTD help to improve the forecast of the tropospheric water vapour content and the quantitative precipitation forecast. We have also assessed through single observation experiments the influence of the formulation of the observation operator which is used to compute the model equivalent ZTD.
\end{abstract}

\section{Introduction}

Tropospheric water vapour is highly variable in space and time and, besides, is a key-ingredient for the success of finescale heavy rainfall forecast (Ducrocq et al., 2002). Lack of high-resolution water vapour observations is one of considerable sources of inaccuracy in model analyses that are used as initial conditions of the numerical weather prediction models (Kuo et al., 1996). The Zenith Total Delays (ZTD) deduced from GPS measurements are attractive for providing tropospheric water vapour data in a context of an increasing number of ground-based GPS receivers.

In the present study, we examine the impact of mesoscale ZTD data assimilation on the fine scale $(2.4-\mathrm{km})$ forecast of a Mediterranean heavy precipitation event. The impact is eval-

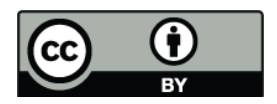

Correspondence to: X. Yan

(xin.yan@cnrm.meteo.fr) uated more specifically for the 5 to 9 September 2005 period, during which several precipitating systems affected Southeastern France. The cumulative surface rainfall during the whole period was over $300 \mathrm{~mm}$ over a significant part of the region, reaching locally more than $500 \mathrm{~mm}$.

Section 2 presents the ZTD assimilation methodology using the 9.5-km 3DVAR ALADIN data assimilation system. Section 3 evaluates the impact of the formulation of the observation operator based on a single observation assimilation experiment. Then, Sect. 4 discusses the impact of assimilating GPS data on the high-resolution forecast of the 5-9 September 2005 rainy event, based on non-hydrostatic 2.4-km MESO-NH simulations. The conclusions follow in Sect. 5 .

\section{Description of the ZTD assimilation}

\subsection{The 9.5-km 3DVAR assimilation system}

The assimilation of ZTD is performed with the ALADIN 3DVAR data assimilation scheme, which has been running operationally at Météo-France since July 2005 (Fischer et al., 2005; Montmerle et al., 2007). To evaluate the impact of assimilating ZTD GPS data, two sets of six-hourly forecastanalysis cycles are run from 1st to 10th of September 2005 with the 3DVAR assimilation system. For the first set, called hereafter CTRL, the observations usually included in the operational 3DVAR ALADIN are assimilated. The latter include observations from radio-soundings, screen-level stations, wind profilers, buoys, ships and aircraft. The following satellite data are also assimilated: horizontal winds from atmospheric motion vectors (AMVs) and the Quickscatt scatterometers, Advanced Microwave Sounding Unit (AMSU)-A and -B radiances and Atmospheric Administration (NOAA)$15,-16,-17$ and the AQUA satellites, High-resolution Infrared Sounder (HIRS) radiances from NOAA-17 and clear

Published by Copernicus Publications on behalf of the European Geosciences Union. 


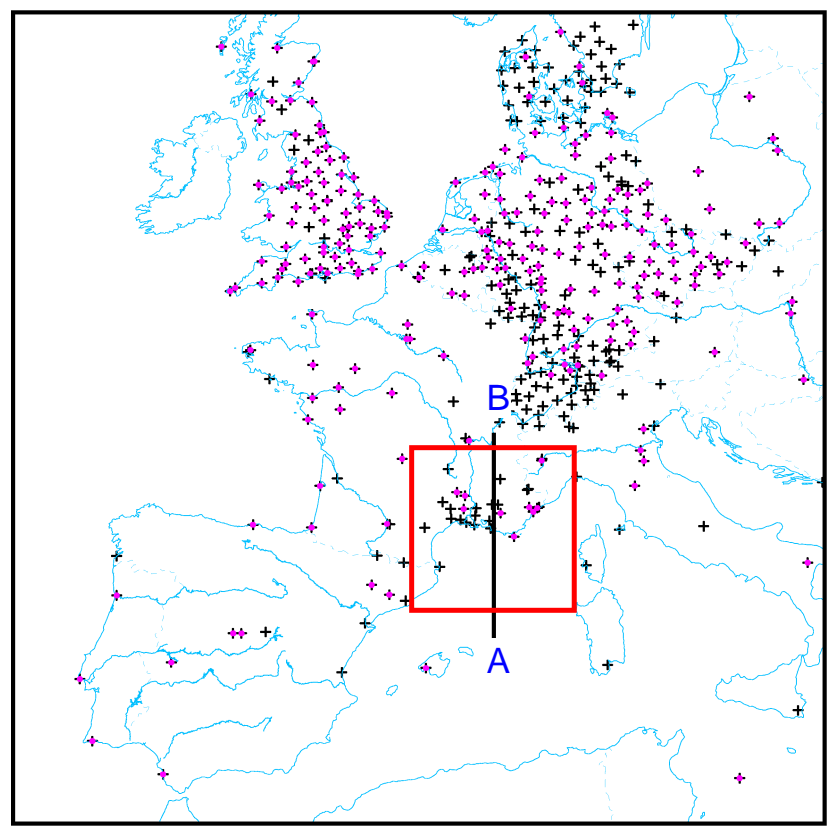

Fig. 1. Location in the 3DVAR ALADIN domain of the GPS stations of the E-GVAP and OHM-CV networks for September 2005. The pink-circled stations are those selected for data assimilation. The A-B line indicates the location of the cross-sections shown in Fig. 2. The 2.4-km MESO-NH domain is delineated by the red box.

SEVIRI radiances from the METEOSAT- 8 satellite. The second set, called GPS, assimilates in addition the ZTD observations.

\subsection{GPS ZTD data}

In the GPS data assimilation cycle, we assimilate GPS data arising from the European GPS station network (E-GVAP, http://egvap.dmi.dk/) and from a 32-stations research network deployed within the Mediterranean Cévennes-Vivarais hydrometeorological Observatory (OHM-CV, Delrieu et al., 2005). For the studied period, data from more than 450 stations covering all the Western Europe were thus available (Fig. 1).

One GPS station can be processed by several analysis centers, leading to several ZTD time-series for a given station. For the assimilation, in order to have a uniform dataset per station, we select only one solution per station by applying the pre-processing developed by Poli et al. (2007) (called hereafter POLI07), slightly modified in order to take into account the higher resolution data assimilation system used in our study. The pre-processing selects pairs of station-center verifying that the first-guess departure follows a Gaussian distribution (The first-guess departure is defined as the difference between observed ZTD and model equivalent ZTD computed from the 6-hour ALADIN forecast which acts as the first-guess in the assimilation cycle). The difference be- tween the station height and the model ground surface height should also be less than $150 \mathrm{~m}$. Station-center pairs with large time availability, small standard deviation of the firstguess departure or the most Gaussian distribution are preferred. Within the assimilation window $( \pm 3 \mathrm{~h}$ around the analysis time), the GPS observation which is the closest to the analysis time is chosen. The pre-processing of GPS data retains at the end 262 stations out of 481 stations (Fig. 1).

To ensure that the observations meet the hypothesis of unbiased errors assumed in the assimilation scheme, the ZTD data are bias-corrected before the assimilation following the method used by POLI07. The bias is computed for each station-center pair based on a 15-day average of first-guess departure between 15 and 31 August 2005.

\section{Sensitivity to the observation operator}

To study the impact of how the model equivalent ZTD is calculated in the assimilation system, we perform analyses where the 3DVAR ALADIN system only assimilates one zenith delay observation using two different observation operators available, as their tangent-linear and adjoint codes, in the assimilation software. The first one has been used by POLI07 and the second one has been proposed by Brenot et al. (2006) (called hereafter BREN06) which had evaluated many expressions to calculate the model equivalent ZTD. POLI07 integrates from the bottom to the top of the model the following equation, using the total pressure $P$, the temperature $T$ and the partial pressure of water vapor $e$ of the atmospheric model column:

$\mathrm{ZTD}=\int\left(k_{1} \frac{P}{T}+k_{3} \frac{e}{T^{2}}\right) d z$

with $k_{1}=0.776 \cdot 10^{-6} \mathrm{~Pa}^{-1} \cdot \mathrm{K}, k_{3}=3730 \cdot 10^{-6} \mathrm{~Pa}^{-1} \cdot \mathrm{K}^{2}($ Smith and Weintraub, 1953).

The equation for BREN06 is the following:

$\mathrm{ZTD}=\int\left(k_{1} \frac{P}{T_{v}}+k_{2}^{\prime} \frac{e}{T}+k_{3}^{\prime} \frac{e}{T^{2}}\right) d z+\Delta Z T D_{\mathrm{TOP}}$

with $k_{2}=0.704 \cdot 10^{-6} \mathrm{~Pa}^{-1} \cdot \mathrm{K}, k_{3}^{\prime}=3739 \cdot 10^{-6} \mathrm{~Pa}^{-1} \cdot \mathrm{K}^{2}$, and $k_{2}^{\prime}=k_{2}-k_{1} \frac{R_{d}}{R_{v}}$ (Bevis et al, 1994); $T_{v}$ being the virtual temperature, $R_{d}=287.0586 \mathrm{~J} /(\mathrm{kmol} . \mathrm{K})$ and $R_{v}=461.525$ $\mathrm{J} /(\mathrm{kmol} . \mathrm{K})$ the specific molar gas constants for dry air and water vapour, respectively.

BREN06 have evaluated different sets of $\left(k_{1}, k_{2}, k_{3}\right)$ coefficients proposed in the literature for ZTD values computed from high-resolution $(2.4 \mathrm{~km})$ non-hydrostatic atmospheric simulated fields. The results showed that there is no significant differences in the evaluation of ZTD between most of the coefficient sets (with a mean bias of ZTD less than $2 \mathrm{~mm}$ ), except for the set using the two-coefficient formula, which presents a mean ZTD bias reaching nearly $12 \mathrm{~mm}$. A ZTD contribution above the model top level $\triangle Z T D_{\mathrm{TOP}}$ is 
a)

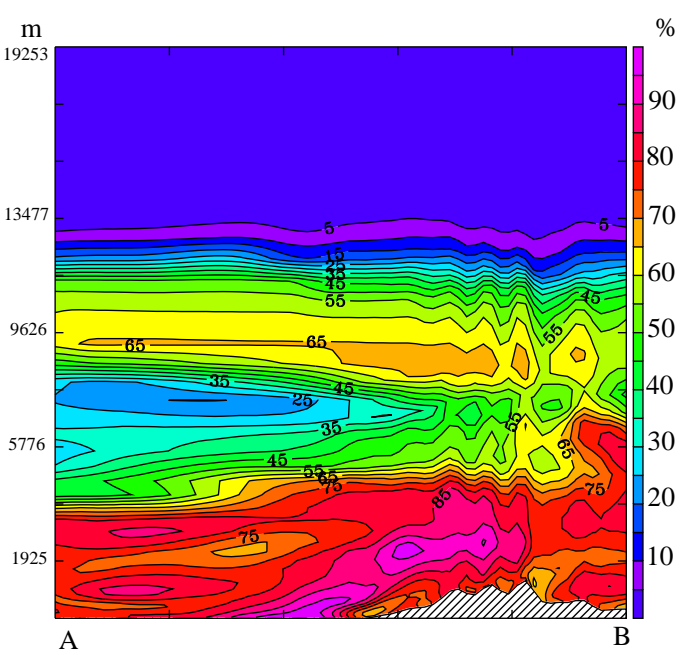

C)

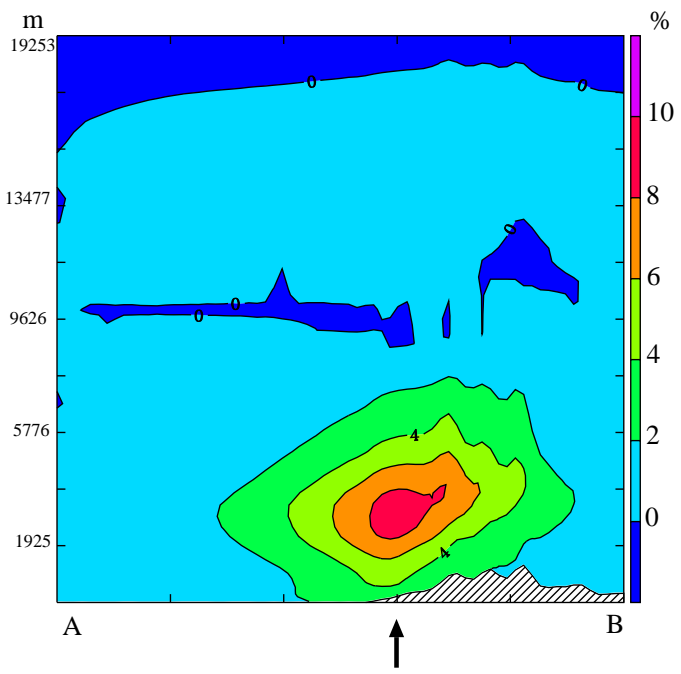

b)

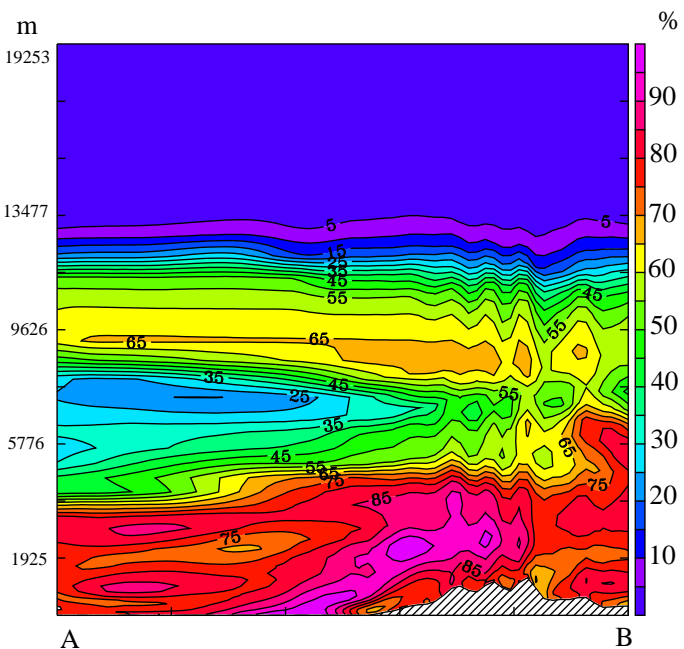

d)

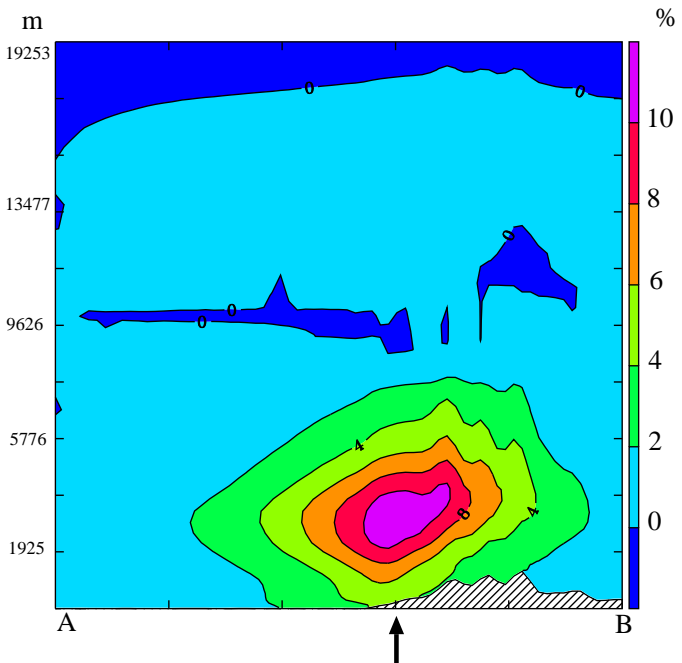

Fig. 2. Vertical cross section along the $670-\mathrm{km}$ line A-B shown in Fig. 1 of analyses and analysis increments of relative humidity, obtained by assimilation of a single ZTD observation using the BREN06 (ac) or the POLI07 (bd) observation operator. Panels ab display the relative humidity from the 3DVAR analysis and panels cd the analysis increment of relative humidity (the analysis increment being defined as the difference between the analysis and the first-guess). The vertical arrows in panels cd indicate the location of the ZTD observation.

also added in BREN06. POLI07 did not consider this constant correction in their observation operator and left this to be handled by their bias correction scheme. $\triangle Z T D_{\text {top }}$ in BREN06 is computed according to Saastamoinen (1972):

$\triangle Z T D_{\mathrm{TOP}}=10^{-6} \frac{k_{1} R_{d} P_{\mathrm{TOP}}}{g_{\mathrm{TOP}}}$

with $P_{\mathrm{TOP}}$ and $g_{\mathrm{TOP}}$ being the pressure and the acceleration of gravity at the top of the model. POLI07 evaluated to $2.3 \mathrm{~mm}$ this constant contribution above the ALADIN/ARPEGE model top at $1 \mathrm{hPa}$.

In order to perform the integration of ZTD operator inside the model, POLI07 and BREN06 follow nearly the same implementation, except when the GPS station is located below the model terrain. In that case, extrapolation of pressure, temperature and humidity values from the model lowest level down to the GPS station altitude is needed. In that extrapolation procedure, the temperature is considered as constant in POLI07 while BREN06 assumes a constant temperature gradient.

Figure 2 shows results of the assimilation of a single observation of ZTD of value $2.4586 \mathrm{~m}$; the model equivalent ZTD computed for the first guess with BREN06 and POLI07 observation operators departs from the observation by $14.34 \mathrm{~mm}$ and $18.6 \mathrm{~mm}$, respectively. Note that $2.3 \mathrm{~mm}$ 
a) All GPS stations in MesoNH domain

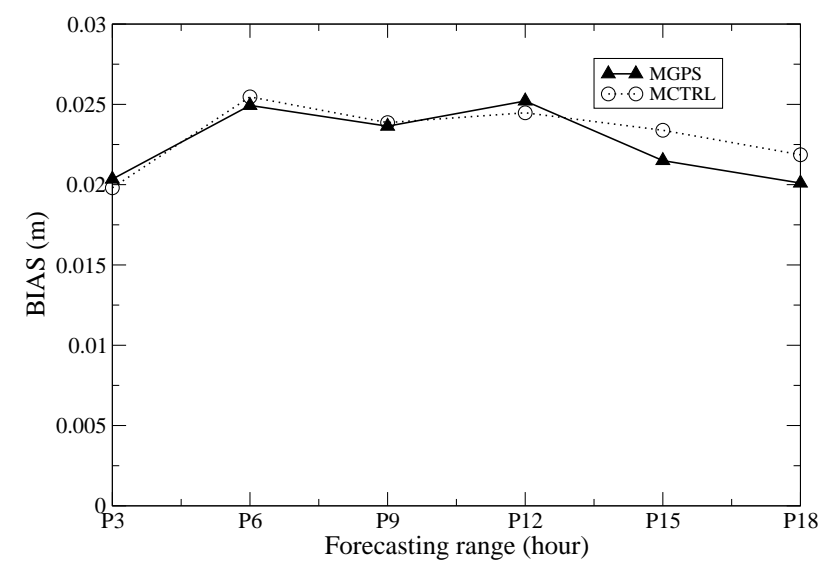

All GPS stations in MesoNH domain

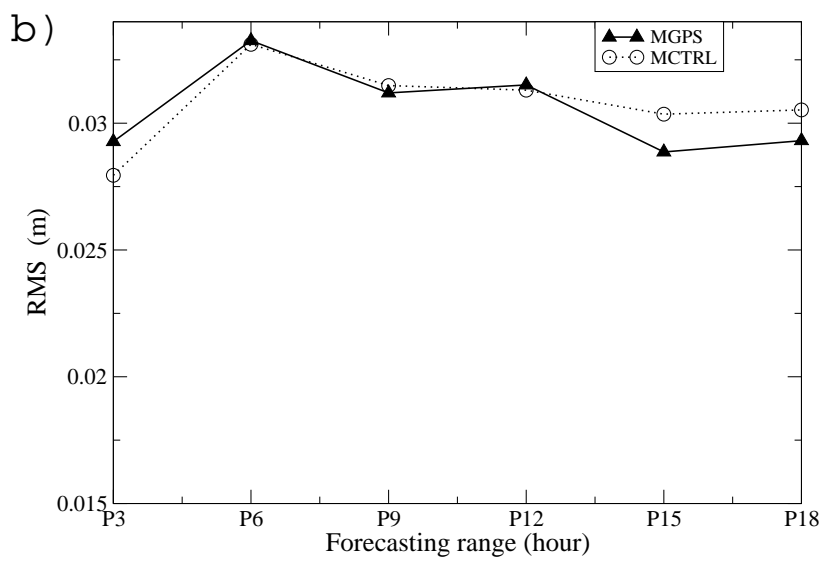

Fig. 3. BIAS and RMS for model equivalent ZTD as function of the forecast range for MGPS and MCTRL MESO-NH runs. Scores are computed against ZTD observations included in the MESO-NH domain (see red box in Fig. 1).The scores are computed gathering all the 3-hourly forecasts of all the MESO-NH 18-h duration runs from 12:00 UTC, 5 September 2005 to 18:00 UTC, 8 September 2005 .

(out of the $18.6 \mathrm{~mm}$ difference) would normally be corrected by a bias correction (as in POLI07) but we neglect this effect here. After the minimization of the cost function in the assimilation, the model equivalent ZTD analysis differs from the observation of only $1.47 \mathrm{~mm}$ for BREN06 and of $1.9 \mathrm{~mm}$ for POLI07, showing a good behaviour of the assimilation with both operators. The main impact of assimilating ZTD data is seen on the humidity field. There is almost no impact on the pressure or temperature field. The horizontal influence range of the observation is in agreement with the horizontal correlation length of the background-error covariance matrix which is about $70 \mathrm{~km}$ in the middle troposphere for specific
Table 1. BIAS and RMS for ZTD simulated by GPS and CTRL MESO-NH experiments against observed ZTD. For the "all GPS stations", scores are computed gathering all the raw ZTD observations over the MESO-NH domain. For the "only assimilated GPS stations", scores are computed only for ZTD values used in the assimilation after removing of the station bias (see Sect. 2.1). The scores are computed gathering all the 3-hourly forecasts of all the MESO-NH 18-h duration runs from 12:00 UTC, 5 September 2005 to $18: 00$ UTC, 8 September 2005 .

\begin{tabular}{ccccc}
\hline & \multicolumn{2}{c}{ all GPS Stations } & \multicolumn{2}{c}{ only assimilated GPS Stations } \\
\hline & MCTRL & MGPS & MCTRL & MGPS \\
BIAS & $23.1 \mathrm{~mm}$ & $22.6 \mathrm{~mm}$ & $14 \mathrm{~mm}$ & $13.4 \mathrm{~mm}$ \\
RMS & $30.8 \mathrm{~mm}$ & $30.6 \mathrm{~mm}$ & $26.9 \mathrm{~mm}$ & $26.2 \mathrm{~mm}$ \\
\hline
\end{tabular}

Table 2. BIAS and RMS for 12-h accumulated precipitation forecast from the MGPS and MCTRL MESO-NH experiments against observed precipitation. The scores are computing gathering all the 12-hourly forecasts (i.e. $0-12 \mathrm{~h}$ and $6-18 \mathrm{~h}$ forecasting ranges) of all the MESO-NH 00:00 UTC and 12:00 UTC runs covering the period from 12:00 UTC, 5 September 2005 to 18:00 UTC, 8 September 2005.

\begin{tabular}{lcc}
\hline & MCTRL & MGPS \\
\hline \multicolumn{3}{c}{ all GPS Stations } \\
BIAS & $0.5 \mathrm{~mm}$ & $0.3 \mathrm{~mm}$ \\
RMS & $19.7 \mathrm{~mm}$ & $20.2 \mathrm{~mm}$ \\
\hline
\end{tabular}

humidity. We can see in Fig. 2cd that the assimilation experiment using POLI07 yields an analysis increment of humidity in the low- to mid- troposphere more intense than in the assimilation experiment using the observation operator from BREN06. The larger analysis increments imply more corrections to the humidity field by the analysis. To summarize, in the present example, the use of different operators can lead to about $2 \%$ of difference in the final analysis increment of humidity, without however modifying the vertical distribution of the humidity analysis increment.

\section{Impact on the fine scale forecasts}

The impact of the ZTD assimilation on the convective scale forecast of the 5-9 September 2005 Mediterranean heavy precipitation episode has been assessed, using two-way gridnesting MESO-NH domains at $9.5-\mathrm{km}$ and $2.4-\mathrm{km}$, respectively. Ducrocq et al. (2002), Lebeaupin et al. (2006) and Nuissier et al. (2008) provided a comprehensive description of this MESO-NH model configuration, that was successfully used for simulating Mediterranean heavy precipitation events in these studies. The 3DVAR ALADIN analyses issued from the two assimilation cycles with and without ZTD data assimilation, as described in Sect. 2, are used as initial 
a)

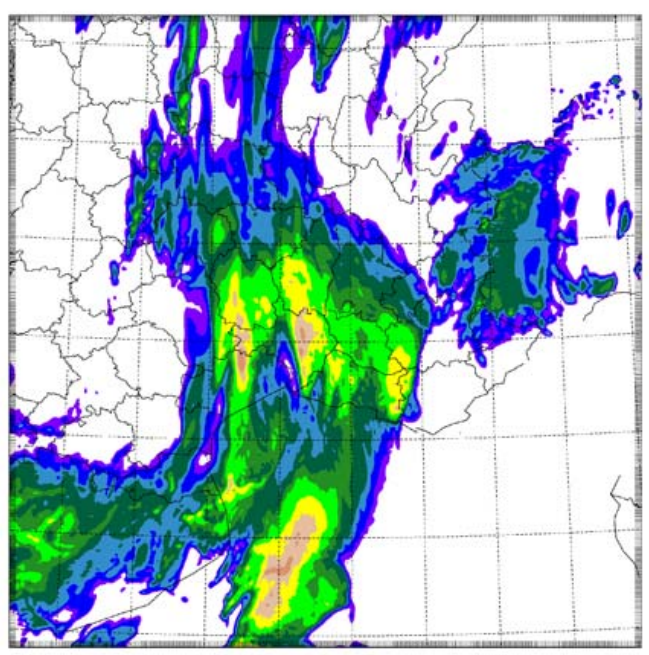

C)

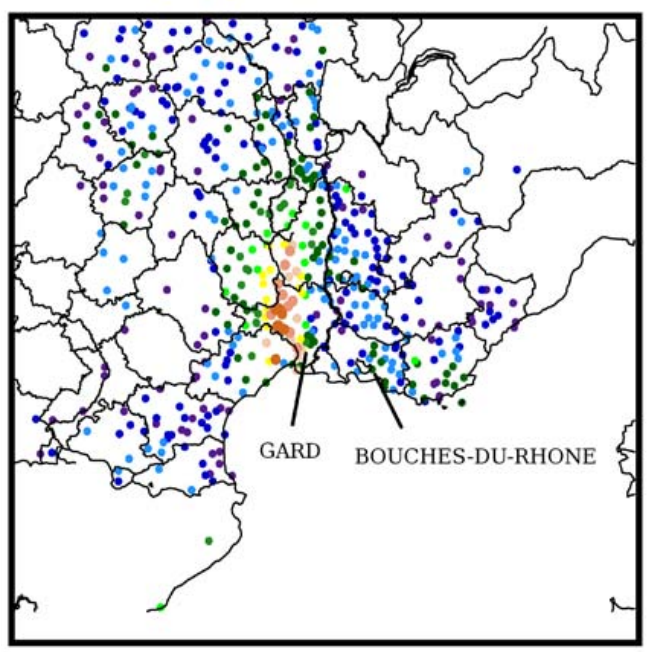

b)

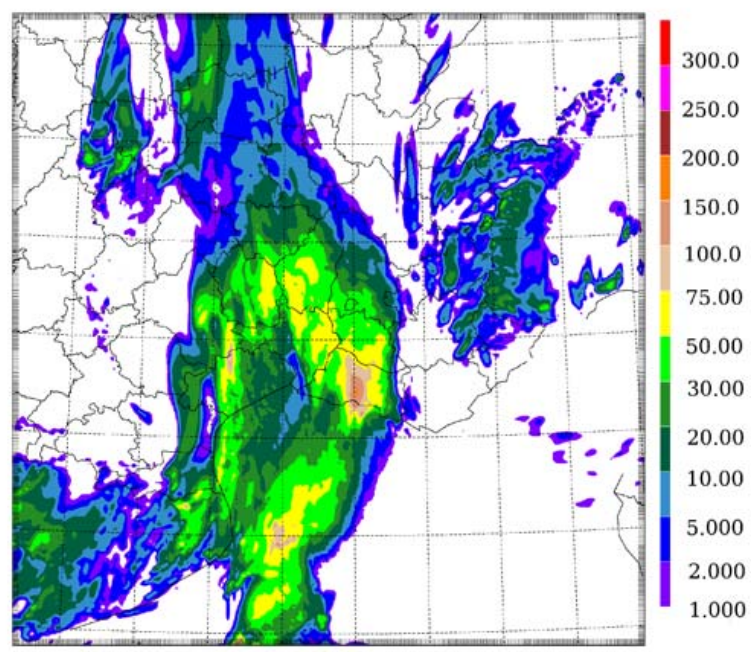

d)

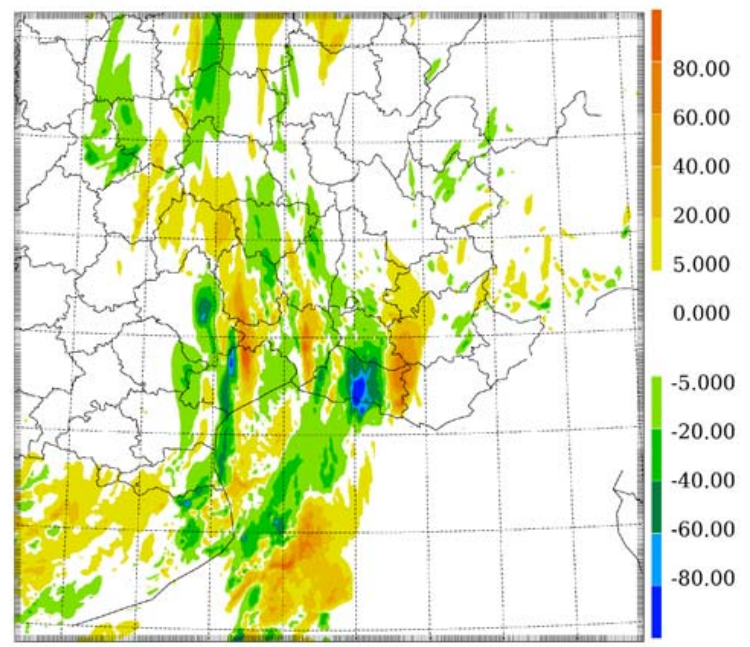

Fig. 4. 12-h accumulated precipitation (mm) from 00:00 UTC to 12:00 UTC, 6 September 2005 for: (a) MGPS MESO-NH run starting from the GPS ALADIN analysis at 00:00 UTC; (b) MCTRL MESO-NH run starting from the CTRL ALADIN analysis at 00:00 UTC; (c) raingauges; (d) differences between MGPS and MCTRL 12-h accumulated precipitation.

conditions to the MESO-NH simulations. Two 18-hourduration MESO-NH runs were issued every day at 00:00 and 12:00 UTC from 12:00 UTC, 5 September to 00:00 UTC, 8 September 2005, covering the whole rainy period. The MESO-NH set using the 3DVAR ALADIN analyses with ZTD data assimilation is called MGPS hereafter, whereas the other one is called MCTRL. We focus here on results of the 2.4-km MESO-NH runs.

The model equivalent ZTD at the GPS stations have been computed for every 3-hourly forecasts from 3 to $18 \mathrm{~h}$ range issued from the two sets of MESO-NH runs. Figure 3 shows the bias and Root Mean Square error (RMS) computed against observed ZTD for all the GPS stations included in the 2.4-km MESO-NH domain (Fig. 1). Scores for MGPS runs show an improved forecast of ZTD for the longer ranges (15 and 18-h ranges) compared to MCTRL. BIAS and RMS are quite similar for the two MESO-NH sets for the very shortrange (Fig.3). The BIAS and RMS computed over all the 3-hourly forecasts, whatever the forecasting ranges, lead to the same conclusion of slightly better results for the MGPS runs (Table 1, left columns). If the scores are computed only on the subset of GPS stations assimilated in the 3DVAR ALADIN system (Table 1, right columns), the MGPS runs are also found better. Note that the BIAS is weaker on that 
FBIAS of $12 \mathrm{H}$ accumulated precipitations

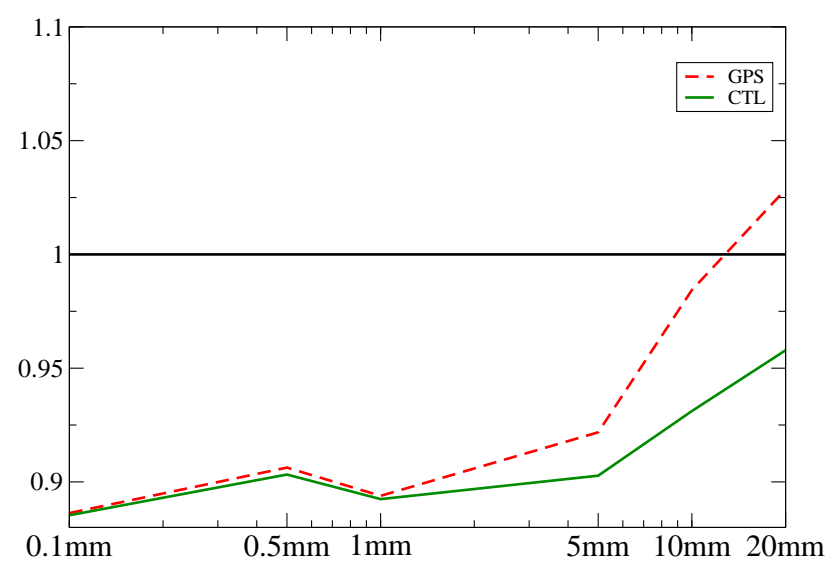

Fig. 5. FBIAS for 12-h accumulated precipitation forecast from the MGPS and MCTRL MESO-NH experiments against observed precipitation. FBIAS is computing gathering all the 12-hourly forecasts (i.e. $0-12 \mathrm{~h}$ and $6-18 \mathrm{~h}$ forecasting ranges) of all the MESONH 00:00 UTC and 12:00 UTC runs covering the period from 12:00 UTC, 5 September 2005 to 18:00 UTC, 8 September 2005.

subset than on the whole GPS data-set because the scores are computed on the biases-corrected ZTD values used for the 3DVAR assimilation. So, using as initial conditions an analysis in which ZTD data have been assimilated improves the forecast of zenith total delay and thus of tropospheric water vapour.

The impact of assimilating GPS on the high-resolution quantitative precipitation forecast is also found slightly positive. Figure 4 shows the 12-h accumulated precipitation results of MGPS and MCTRL runs issued from the corresponding GPS and CTRL Aladin analysis at 00:00 UTC, 6 September 2005. Compared with the raingauge data (Fig. 4c), we could see that MGPS run locates better the heavy precipitation region over the GARD department while MCTRL run misplaces the heavy precipitation area over the BOUCHES-DU-RHONE department. The differences reach more than $80 \mathrm{~mm}$ in some locations(Fig. 4d) between these two runs (MGPS-MCTRL). Table 2 shows the BIAS and RMS computed over every 12-h accumulated precipitation totals (i.e. $0 \mathrm{~h}-12 \mathrm{~h}$ and $6 \mathrm{~h}-18 \mathrm{~h}$ forecast ranges) for the MGPS and MCTRL runs. Scores are computed against raingauge observations in the 2.4-km MESO-NH domain, which counts about 220 raingauges. The MGPS set improves the BIAS whereas the RMS is slightly weaker for the MCTRL runs. Figure 5 shows the Frequency Bias (FBIAS, Bougeault (2003)) for precipitation events with observed 12-h accumulated rainfall above $0.1 \mathrm{~mm}, 0.5 \mathrm{~mm}, 1 \mathrm{~mm}, 5 \mathrm{~mm}, 10 \mathrm{~mm}$ and $20 \mathrm{~mm}$. FBIAS indicates whether the experiment has a tendency to under-forecast $(\mathrm{FBIAS}<1)$ or to over-forecast (FBIAS $>1$ ) precipitation events, with a perfect score being
1. For all the thresholds, the MGPS experiment shows an improved skill compared to the MCTRL, especially for the higher precipitation events. FBIAS for the two experiments indicate a tendency to under-forecast the events for weak thresholds.

\section{Conclusions}

The impact of assimilating Zenith Total delay (ZTD) observations from a dense GPS network has been evaluated for the high-resolution forecast of the heavy precipitation event of 5-9 September 2005 over Mediterranean northwestern coasts. Using as initial conditions the analyses in which GPS ZTD data have been assimilated leads to a weak positive impact on the quantitative precipitation forecasts issued by the convective scale MESO-NH model. A better forecast of the model equivalent ZTD and thus of the tropospheric water vapour are also found.

The impact of the formulation of the observation operator has also been studied through a single observation experiment. Two slightly different observation operators showed that the assimilation of ZTD modifies mainly the low to midtroposphere moisture. The main difference between the two operators lie in the amplitude of the relative humidity increments, only reflecting larger first-guess differences in one operator (some of these differences are explained by a constant model top contribution). Almost no difference is found for the vertical distribution of analysis increment of relative humidity in both cases.

A more comprehensive analysis of the 3DVAR ALADIN ZTD assimilation over the whole September 2005 month is the subject of a companion paper. Work is in progress to assimilate ZTD data directly at the convective scale using a 2.5-km data assimilation system and evaluate its impact on the quantitative precipitation forecast. A finer scale model is expected to reduce the height differences between the GPS station and the model orography, and therefore to improve the accuracy of the observation operator.

Acknowledgements. The authors would like to thank the E-GVAP project for their efforts in making European ground-based GPS data available in near real time. The authors are grateful to the constructive comments made by Romu Romero. The OHM-CV GPS network and this study benefited from support from the national research program LEFE, the Institut National des Sciences de l'Univers, and of the European Commission through the FP6/PREVIEW project.

Edited by: A. Mugnai

Reviewed by: R. Romero 


\section{References}

Bevis, M., Businger, S., Chiswell, S., Herring, T. A., Anthes, R. A., Rocken, C., and Ware, R. H.: GPS Meteorology: Mapping Zenith Wet Delays onto Precipitable Water, J. Appl. Meteor., 33, 379-386,1994.

Bougeault, P.: The WGNE survey of verification methods for numerical prediction of weather elements and severe weather events, CAS/JSC WGNE Report, 18, WMO/TD-NO.1173, Appendix C, 1-11, 2003.

Brenot, H., Ducrocq, V., Walpersdorf, A., Champollion, C., and Caumont, O.: GPS Zenith Delay Sensitivity evaluated from High-Resolution NWP Simulations of the 8-9th September 2002 Flash-Flood over Southeastern France, J. Geophys. Res., 111, D15105, doi:10.1029/2004JD005726, 2006.

Delrieu G., Ducrocq, V., Gaume, E., Nicol, J., Payrastre, O., Yates, E., Kirstetter, P. E., Andrieu, H., Ayral, P.-A., Bouvier, C., Creutin, J.-D., Livet, M., Anquetin, S., Lang, M., Neppel, L., Obled, C., Parent-du-Chatelet, J., Saulnier, G.-M., Walpersdorf, A., and Wobrock, W.: The catastrophic flash-flood event of 8-9 September 2002 in the Gard region, France: a first case study for the Cévennes-Vivarais Mediterranean, Hydro-meteorological Observatory, J. Hydrometeorol., 6, 34-52, 2005.

Ducrocq, V., Ricard, D., Lafore, J. P., and Orain, F.: Storm-Scale Numerical Rainfall Prediction For Five Precipitating events over France: On the Importance of the initial humidity field, Weather Forecast, 17, 1236-1256, 2002.

Fischer, C., Montmerle, T., Berre, L., Auger, L., and Stefanescu, S. E.: An overview of the variational assimilation in the ALADIN/FRANCE NWP system, Q. J. Roy. Meteor. Soc., 131, 3477-3492, 2005.
Kuo, Y.-H., Zou, X., and Guo, Y.-R.: Variational assimilation of precipitable water using a non-hydrostatic mesoscale adjoint model. Part I: Moisture retrieval and sensitivity experiments, Mon. Weather. Rev., 124, 122-147, 1996.

Lebeaupin, C., Ducrocq, V., and Giordani, H.: Sensitivity of Mediterranean torrential rain events to the sea surface temperature based on high-resolution numerical forecsats, J. Geophys. Res., 111, D12110, doi:10.1029/2005JD006541, 2006.

Montmerle, T., Rabier, F., and Fischer, C.: Respective impact of polar orbiting and geostationary satellite observations in the Aladin/France NWP system, Q. J. Roy. Meteor. Soc., 133, 655-671, 2007.

Nuissier, O., Ducrocq, V., Ricard, D., Lebeaupin, C., and Anquetin, S.: A numerical study of three catastrophic precipitating events over Western Mediterranean region (Southern France). Part I: Numerical framework and synoptic ingredients, Q. J. Roy. Meteor. Soc., 134, 111-130, 2008.

Poli, P., Moll, P., Rabier, F., Desroziers, G., Chapnik, B., Berre, L., Healy, S. B., Andersson, E., and EI Guelai, F.-Z.: Forecast impact studies of zenith total delay data from European near realtime GPS stations in Meteo France 4DVAR, J. Geophys. Res., 112, D06114, doi:10.1029/2006JD007430, 2007.

Saastamoinen, J.: Introduction to practical computation of astronomical refraction, Bull. Geod., 106, 389-397, 1972.

Smith, E. and Weintraub, S.: The constants in the equation for atmospheric refractive index at radio frequencies, Proc. IRE, 1035$1037,1953$. 